\title{
Beta-glucan feeding effect on biochemical and immune responses in vaccinated and non-vaccinated piglets against proliferative enteropathy
}

\author{
Jana Soročinová ${ }^{2}$, Peter Reichel ${ }^{1}$, Dagmar Mudroňováa ${ }^{3}$ Jaroslav Novotný ${ }^{1}$, Róbert Link ${ }^{1}$, \\ Lenka Leškováa ${ }^{2}$ Michal Smaržik ${ }^{2}$, Herbert Seidel ${ }^{1}$, Miroslav Húska ${ }^{1}$, Vladimír Macák ${ }^{1}$, \\ Soňa Dobolyová, Katarína Kovačocyová ${ }^{1}$
}

\begin{abstract}
${ }^{1}$ University of Veterinary Medicine and Pharmacy, Clinical Department for Swine, ${ }^{2}$ Clinical Department for Ruminants, ${ }^{3}$ Department of Microbiology and Immunology, Košice, Slovakia
\end{abstract}

Received July 18, 2012

Accepted April 23, 2013

\begin{abstract}
The aim of this study was to compare the results of active non-specific immuno-modulation in form of feeding food additive based on beta-glucan to pregnant sows and consecutive specific immuno-modulation by vaccination of their sucklings. Experimental sows were fed feedstuff with preparation on basis of beta-glucan at a $5 \%$ concentration from day 14 before parturition until the weaning of piglets; control sows were fed standard feedstuff only. Sucklings were vaccinated with a single dose of $2 \mathrm{ml}$ of oral vaccine Enterisol ${ }^{\mathbb{R}}$ Ileitis one week before weaning. Collection of biological material was done $3 \times$ in sows and $5 \times$ in sucklings. Postvaccination examination of blood serum for antibodies against $L$. intracellularis in sucklings in experimental and control groups was negative, probably due to insufficiently long period of rejection of antibiotics-medicated feedstuff and by chlorinated water. With the exception of immunological profile, no essential changes were recorded in the dynamics of other indices of examined profiles in groups of sows in relation to immune-modulation. In groups of sucklings from sows fed beta-glucan supplemented feedstuff significant changes were determined for various indices compared with sucklings from sows fed standard foodstuff. This is the first similar study in pig herds in Slovakia.
\end{abstract}

Swine, Lawsonia intracellularis, antibodies, dynamics of profiles

Porcine proliferative enteropathy (PPE, ileitis, proliferative enteropathy, lawsoniosis) is along with salmonellosis and dysentery of swine, one of the most distinguished diarrhoeal diseases in the pre-feed up and feed up periods in swine (Podmanický et al. 1999). The causal agent of the disease is compulsory intra-cellular bacteria Lawsonia intracellularis belonging to the Desulfovibrionaceae family which propagates in the cells of intestinal epithelium. It causes significant economic losses by low conversion of feedstuff and by high costs for drugs; there are also losses caused by fallen stock (Podmanický et al. 1999). In Europe, $34-67 \%$ of swine and $88-100 \%$ of breedings are infected with $L$. intracellularis (Šajgalík 2007). Based on the latest evidence, the prevalence of this disease in Slovakia is $12-50 \%$ (Podmanický and Kováč 2000).

It is generally known that beta-glucans as matters of natural origin have potential immune-modulating effects (Eicher et al. 2006). The adaptive immune system responds to introduced foreign antigens, involving both $\mathrm{B}$ and $\mathrm{T}$ cells. $\mathrm{B}$ cells produce antibodies to mediate humoral immunity; $T$ cells induce cell-mediated immunity. The adaptive immune response also involves dendritic cells (DC) derived from monocytes, and these present antigens to T cells for activation of immune responses (Munz et al. 2005).

The aim of this study was to perform an experiment on weaned piglets. It was expected that after immune-modulation of sows and high trans-colostral transfer of immunoglobulines, the piglets would produce higher amounts of specific antibodies after oral vaccination with Enterisol ${ }^{\circledR}$ Ileitis vaccine against Lawsonia intracellularis.

Address for correspondence:

MVDr. Jana Soročinová

Clinic for Swine

University of Veterinary Medicine and Pharmacy in Košice

Komenského 73, 04181 Košice, Slovakia

Phone: +421904 169004

E-mail: jana.sorocinova@gmail.com

http://actavet.vfu.cz/ 


\section{Materials and Methods}

Animals and experimental design

The experiment was carried out on a middle-sized pig farm in the south of Slovakia. In total, 20 sows and their 36 selected piglets were included in the experiment. The animals were crossbreeds of Large White and Landrace. The sows were divided into two groups: experimental $(\mathrm{n}=10)$ and control $(\mathrm{n}=10)$. Experimental sows were fed feedstuff with preparation on basis of beta-glucan (Imunol P, Polychem spol. s r.o., Slovakia) at a $5 \%$ concentration ( $5 \mathrm{~kg}$ in $100 \mathrm{~kg}$ of feedstuff) from day 14 before parturition until the weaning of piglets (day 28); control sows were fed standard feedstuff only. the composition of Imunol P is presented in Table 1.

Table 1. Composition of dietary additive Imunol P (data from producer).

\begin{tabular}{lc}
\hline Compound & Content $(\%$ weight $)$ \\
\hline Beta-1,3/1,6-D-glucan & 0.8 \\
Zeolite & 38.8 \\
Glycerol & 34.0 \\
Silica oxide & 16.7 \\
Water & 9.6 \\
$\mathrm{NaCl}_{3}$ & 9.0 \\
$\mathrm{Cholinchloride}$ & $4.5 \cdot 10^{-3}$ \\
DL-methionine & $0.9 \cdot 10^{-3}$ \\
$\mathrm{ZnCl}_{2}$ & $0.8 \cdot 10^{-3}$ \\
$\mathrm{E}^{-v i t a m i n}($ alpha tocopherol $100 \%$ weight $)$ & $8.9 \cdot 10^{-5}$ \\
Beta carotene & $3.8 \cdot 10^{-5}$ \\
$\mathrm{CoCl}_{2} \cdot 6 \mathrm{H}_{2} \mathrm{O}$ & $1.8 \cdot 10^{-5}$ \\
$\mathrm{~B}_{3}$-vitamin (niacin $\left.100 \%\right)$ & $1.6 \cdot 10^{-5}$ \\
$\mathrm{KI}$ & $0.6 \cdot 10^{-5}$ \\
$\mathrm{Na}_{2} \mathrm{SeO}_{3} \cdot 5 \mathrm{H}_{2} \mathrm{O}$ & $0.4 \cdot 10^{-5}$ \\
\hline
\end{tabular}

Collection of biological material in sows was done three times: 14 days before parturition (sampling 0), during parturition (sampling 1), and during the weaning of piglets (sampling 2). Blood was taken by venepuncture from vena cava cranialis. Sucklings were divided into 4 groups (A, B, C, D) depending on the intake of betaglucan by their mothers and also depending on vaccination against Lawsonia intracellularis (Table 2). Sucklings were vaccinated with a single dose of $2 \mathrm{ml}$ of oral vaccine (Enterisol ${ }^{\circledR} \quad$ Ileitis, Boehringer Ingelheim $\mathrm{GmbH}$, Germany) by oral drencher one week before weaning. In sucklings the samples were collected five times (samplings $0-4$ ): immediately after birth, and on days $14,28,35$ and 60 after birth. Blood was taken by venepuncture from sinus opthalmicus.

\section{Sample analysis}

Blood samples were used for

Table 2. Experimental pigs divided into groups according to intake of beta-glucan and on vaccination against Lawsonia intracellularis.

\begin{tabular}{lccc}
\hline Group & Feeding & Piglets & Vaccination \\
\hline Experimental sows & \multirow{2}{*}{ Feedstuff + Imunol P } & A $(\mathrm{n}=9)$ & + \\
$(\mathrm{n}=10)$ & & $\mathrm{B}(\mathrm{n}=9)$ & - \\
Control sows & Feedstuff & $\mathrm{C}(\mathrm{n}=9)$ & - \\
$(\mathrm{n}=10)$ & & $\mathrm{D}(\mathrm{n}=9)$ & + \\
\hline
\end{tabular}
analysis of chosen indices of hepatic, protein, energetic, and haematological profile with differential white blood count, immunological profile and representation of sub-populations of lymphocytes.

Indices of hepatic, protein, and energetic profiles in the blood serum were determined by automatic analyser ALIZE (Lisabio, France) using commercially made Randox kits. Analysis of haematological indices was done on haematologic analyser ABX Micros ABC Vet (HORIBA Medical, France). Differential white blood count was checked microscopically from blood smears (panoptic staining according Pappenheim). Phagocyte activity of leukocytes was analysed by commercial set Phagotest ${ }^{\circledR}$ (ORPEGEN Pharma, Germany) on flow cytometer BD FACSCanto ${ }^{\mathrm{TM}}$ (Becton Dickinson Biosciences, USA) using BD FACS Diva ${ }^{\mathrm{TM}}$ software. Test was made according to applied guide, and 10000 leukocytes were counted for interpretation. Stimulation index of leukocytes (SI) was assessed by commercial test (Cell Proliferation ELISA Kit, BrdU-colorimetric, Roche) and measured by ELISA reader (Pistl et al. 2003). Blood serum total immunoglobulines (TIg) were analysed spectrophotometrically by turbidimetric method with zinc-sulphate test (Slanina et al. 1976). Identification of sub-populations of lymphocytes in peripheral blood was performed by flow cytometry using flow cytometer BD FACSCanto ${ }^{\mathrm{TM}}$ (Becton Dickinson Biosciences, USA) equipped with BD FACS Diva ${ }^{\mathrm{TM}}$ software. Testing of oxidative burst of phagocytes was done by iodine-nitro-tetrazolium test according to Lokaj and Oburkova (1975).

Antibodies against Lawsonia intracellularis were detected by commercial kit BioScreen Ileitis Antibody ELISA (Synbiotics Europe SAS, France), in serum of all sows at samplings 0-2 and in all piglets at samplings $0-4$. 
Statistics

Results of biochemical and immunologic analyses were evaluated in groups based on their average values and standard deviation. Significance was evaluated using the statistical program GraphPad Prism 5. In the group of sows, non-paired $t$-test and one-way analysis of variance ANOVA (Tukey's multiple comparison test) were used; in the groups of piglets one-way analysis of variance ANOVA (Tukey's multiple comparison test) was used. Statistical significance within groups was signed with letters ${ }^{\mathrm{a}}(P<0.05),{ }^{\mathrm{b}}(P<0.01),{ }^{\mathrm{c}}(P<0.001)$ and between groups ${ }^{\mathrm{d}}(P<0.05),{ }^{\mathrm{e}}(P<0.01),{ }^{\mathrm{f}}(P<0.001)$.

\section{Results}

Detectable trans-colostral antibodies against Lawsonia intracellularis in $100 \%$ of positive sows in sampling 0 were mostly detected in groups of piglets from sows fed standard foodstuff $(\mathrm{C}=100 \%$ positive, $\mathrm{D}=67 \%$ positive $)$ and persisted even in sampling 1 at lower percentage $(C=66 \%$ positive or $\mathrm{D}=44 \%$ doubtful), whereas in the experimental groups positivity was proved only in group $\mathrm{B}$ in sampling $0(\mathrm{~B}=22 \%$ positive and $\mathrm{A}=22 \%$ doubtful). Post-vaccination examinations of blood serum for antibodies against L. intracellularis in piglets in the experimental and control groups were negative, thus not confirming the potentiating effect of beta-glucan in this study.

Except for the immunology profile, no significant changes were recorded in the dynamics of other indices of the examined profiles in the groups of sows in relation to immunemodulation, whereas in the experimental groups of sucklings (A, B) significant changes were recorded for various indices compared to control sucklings (C, D).

In all groups of piglets we documented an initial increase in values of total cholesterol (TCH) (beyond the reference norm) and a subsequent decrease (below the reference norm), where the level of TCH values remained until the end of experiment (Fig. 1). A significant decrease in values of TCH was shown in groups of piglets from immune-stimulated (A and B) at sampling 3, which indicates an anti-lipolytic or cholesterol decreasing effect.

The anti-lipolytic effect is also indicated by values of total lipids (TL). Initial values of total lipids in groups of piglets B and D were significantly higher than in the control group C. In sampling 2 the values in group B were significantly lower than in the group C (Fig. 1).

The immune-modulating influence of the food additive containing beta-glucan (IMUNOL P) was demonstrated in sows only partially in the dynamics of immunology profile indices, especially during the parturition period, when significantly higher values of phagocyte activity (FA) were recorded in comparison to the control group (Fig. 2), whereas in the experimental groups of piglets (A, B) significantly higher values of TIg (Fig. 3), FA (Fig. 2), index of metabolic activity of phagocytes (IMA) (Table 3) at weaning period, or at postvaccination period were recorded compared to the control groups of piglets $(C, D)$.

Comparison of results of specification of sub-population of lymphocytes showed significant differences between groups only in case of double-positive CD4CD8 lymphocytes, whereas in piglets we noticed the same favourable trend of changes in observed sub-populations of lymphocytes in peripheral blood compared to the control groups.

Table 3. Index of metabolic activity of phagocytes in peripheral blood in piglets during different samplings.

\begin{tabular}{lcccccc}
\hline \multirow{2}{*}{ Piglets } & \multicolumn{7}{c}{ Sampling } \\
\cline { 2 - 7 } & 0 & 1 & 2 & 3 & 4 & ANOVA* \\
\hline $\mathrm{A}$ & $1.24 \pm 0.18$ & $1.16 \pm 0.02$ & $1.71 \pm 0.14$ & $1.63 \pm 0.07$ & $1.63 \pm 0.02$ & $P<0.001$ \\
$\mathrm{~B}$ & $1.31 \pm 0.19$ & $1.12 \pm 0.10$ & $1.42 \pm 0.13$ & $1.58 \pm 0.09$ & $1.60 \pm 0.28$ & $\mathrm{~ns}$ \\
$\mathrm{C}$ & $1.15 \pm 0.08$ & $1.09 \pm 0.07$ & $1.35 \pm 0.18$ & $1.34 \pm 0.09$ & $1.57 \pm 0.11$ & $P<0.01$ \\
$\mathrm{D}$ & $1.12 \pm 0.07$ & $1.10 \pm 0.06$ & $1.27 \pm 0.13$ & $1.29 \pm 0.13$ & $1.39 \pm 0.03$ & $P<0.05$ \\
\hline
\end{tabular}

A, B, C, D - groups of pigs (see Table 2), ns - non-significant, *Significance within group.

Data are expressed as arithmetic average of measures \pm standard deviation. 

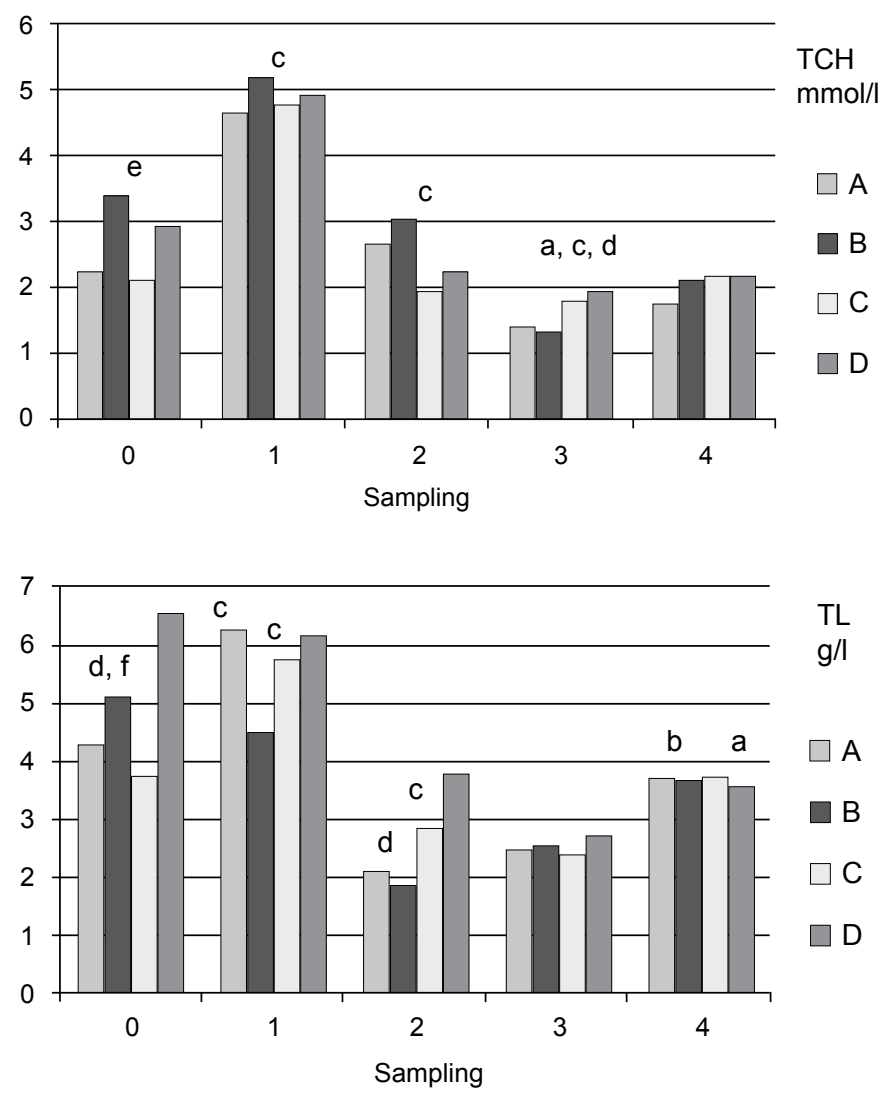

Fig. 1. Dynamics of changes of total cholesterol $(2.6-3.9 \mathrm{mmol} / \mathrm{l})$ and of total lipids $(3.5-5.5 \mathrm{~g} / \mathrm{l})$ in piglets during different samplings.

TCH - total cholesterol, TL - total lipids, A, B, C, D - groups of pigs (see Table 2)

Statistical significance within group: ${ }^{\mathrm{a}} P<0.05,{ }^{\mathrm{b}} P<0.01,{ }^{\mathrm{c}} P<0.001$,

Statistical significance between groups: ${ }^{\mathrm{d}} P<0.05,{ }^{\mathrm{e}} P<0.01,{ }^{\mathrm{f}} P<0.001$

\section{Discussion}

According to the manufacturer, during vaccination with Enterisol ${ }^{\circledR}$ Ileitis, there is a gradual reaction of body and maximum level of antibodies during days 14-21 after vaccination. This was not demonstrated in our experiment according to findings of Kroll et al. (2004), who referred that protection after immunisation initiates after three weeks at the latest after using of preparation and lasts for 17-22 weeks. Vaccine inefficiency is assumed after expiration, inappropriate storage and maintenance, or incorrect dilution of the vaccine before application. These factors were eliminated in our experiment, so we do not consider this as non-success. More probably the cause of this was insufficient length of period of rejection of antibiotics-medicated foodstuff and chlorinated water.

Early studies on the use of beta-glucans in swine were oriented to the study of production indices in an effort to use them as a growth-stimulant with the purpose of replacing antibiotic-medicated foodstuff. Many authors (Miguel et al. 2004; Hahn et 

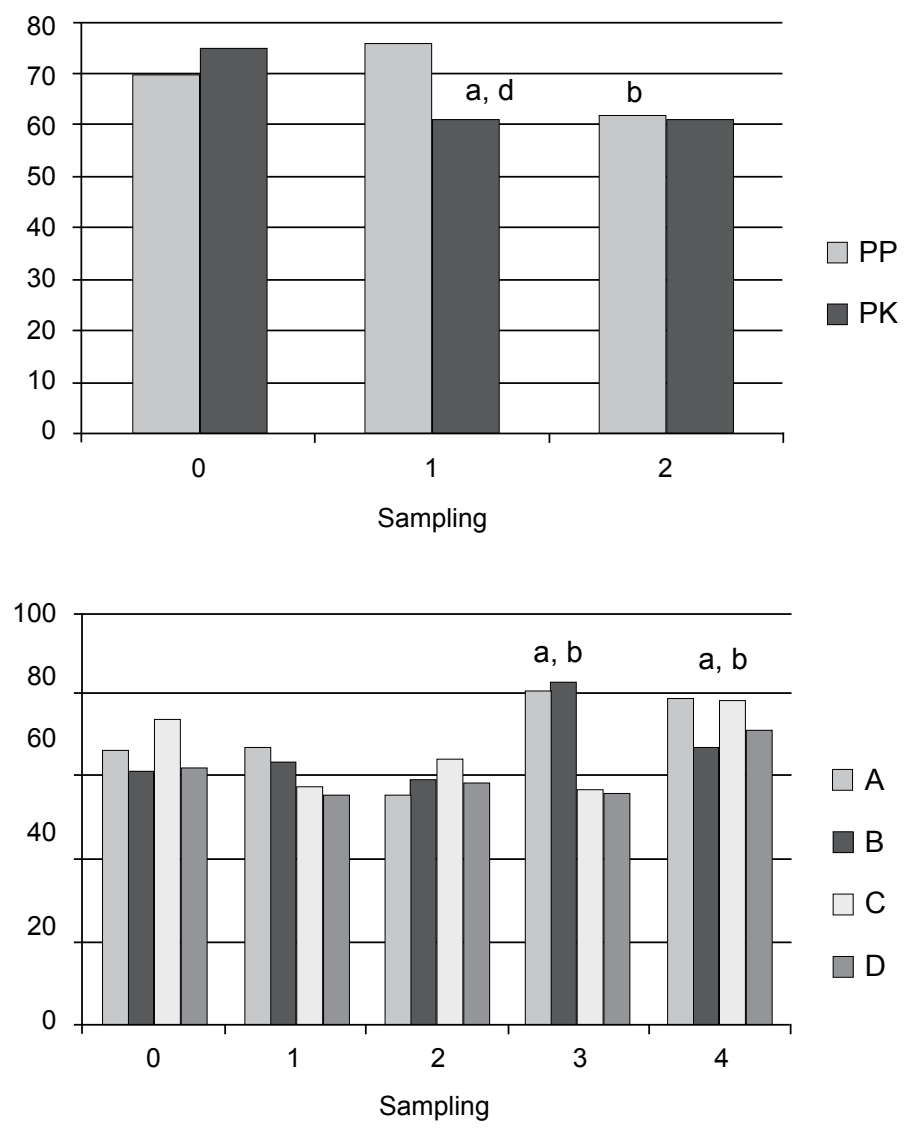

Fig. 2. Phagocyte activity in peripheral blood of sows and piglets during different samplings.

PP - experimental sows, PK - control sows, A, B, C, D - groups of pigs (see Table 2)

Data are expressed as arithmetic mean of measures \pm standard deviation

Significance within group: ${ }^{\mathrm{a}} P<0.05,{ }^{\mathrm{b}} P<0.01$

Significance between groups: ${ }^{\mathrm{d}} P<0.05$

al. 2006; Wang et al. 2008) have mentioned relatively positive results, even if some of them are discussed as conflicting to this day. Beside the reported higher weight gain, there are also reports of their stimulating effect on increased resistance of sucklings against infectious agents, their influence to phagocytic activity of cells and production of reactive forms of oxygen, proliferative activity of lymphocytes, and also expression of specific receptors (Hiss and Sauerwein 2003; Hahn et al. 2006). Multicellular organisms possess receptors called pattern recognition receptors to detect innately non-self structures (including pathogen-associated molecular patterns, or PAMPs). Thus, fungal beta-glucans probably act as PAMPs and are recognized by appropriate cellsurface receptors, initiating immune responses. These are dectin-1, complement receptor 3 (CR3), scavenger receptors, lactosylceramide (LacCer), and the toll-like receptor (Brown and Gordon 2005). Binding of dectin-1 with the ligand activates several signalling pathways to promote innate immune responses through activation of phagocytosis, ROS production, and induction of inflammatory cytokines (Willment et al. 2001; Grunebach et al. 2002). 


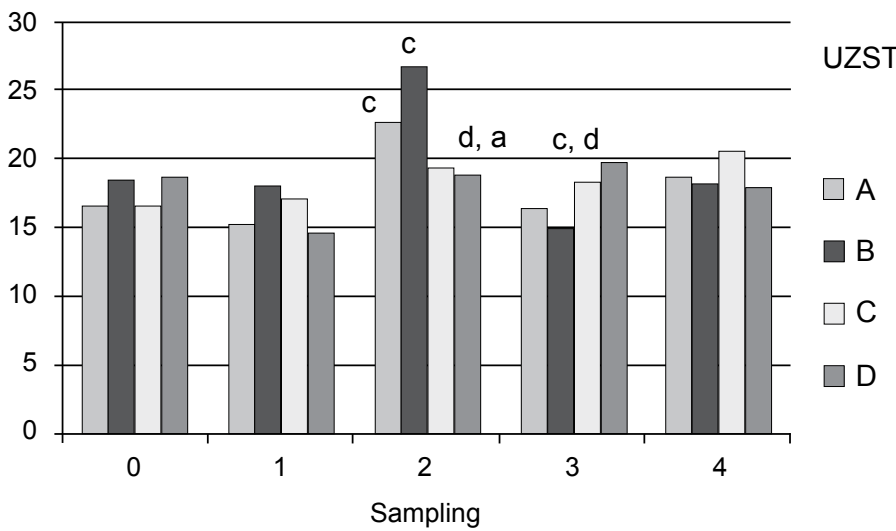

Fig. 3. Dynamics of changes of total immunoglobulins (20-35 units of zinc-sulphate test) in piglets during different samplings.

UZST Unites of zinc-suplhate test

A, B, C, D - groups of pigs (see Table 2)

Statistical significance within group: ${ }^{\mathrm{a}} P<0.05,{ }^{\mathrm{c}} P<0.001$

Statistical significance between groups: ${ }^{\mathrm{d}} P<0.05$

Swine do not have IgD, and in differentiation of lymphocytes gene conversion is not applied. In peripheral lymphocyte population, notable amount of $\gamma \delta$ cells and double-positive $\mathrm{CD}^{+} \mathrm{CD}^{+}$lymphocytes occur (Trebichnavský et al. 2000) which was demonstrated in our study.

Although we did not confirm post-vaccination increase of antibodies against L. intracellularis after beta-glucan feeding in this study, we demonstrated the immunological effect of the additive on some indicators of immunology profile. It would be important to conduct additional similar studies, due to great variability of factors that affect results in field conditions.

\section{Acknowledgements}

This work was supported by Grant Agency for Science, VEGA of the Slovakia, Grant No. 1/0537/12

\section{References}

Brown GD, Gordon S 2005: Immune recognition of fungal b-glucans. Cell Microbiol 7: 471-479

Eicher SD, McKee CA, Carroll JA, Pajor EA 2006: Suplemental vitamin C and yeast cell wall $\beta$-glucan as growth enhancers in newborn pigs and as immunomodulators after an endotoxin challenge after weaning. J Anim Sci 84: $2350-2360$

Grunebach F, Weck MM, Reichert J, Brossart P 2002: Molecular and functional characterization of human dectin-1. Exp Hematol 30: 1309-1315

Hahn TW, Lohakare JD, Lee SL, Moon WK, Chae BJ 2006: Effects of supplementation of $\beta$-glukans on growth performance, nutrient digestibility, and immunity in weanling pigs. J Anim Sci 84: 1422-1428

Hiss S, Sauerwein H 2003: Influence of dietary $\beta$-glucan on growth performance, lymphocyte proliferation, specific immune response and haptoglobin plasma concentrations in pigs. J Anim Physiol Anim Nutr 87: 2-11

Kroll JJ, Roof MB, McOrist S 2004: Evaluation of protective immunity in pigs following oral administration of an avirulent live vaccine of Lawsonia intracellularis. Am J Vet Res 65: 559-565

Lokaj V, Oburková P 1975: Determination of tetrazolium-reductase activity of leukocytes (In Czech). Imunol Zprav 6: $42-44$

Miguel JC, Rodriguez-Zas SL, Pettigrew JE 2004: Efficacy of a mannan oligosaccharide (Bio-Mos ${ }^{\circledR}$ ) for improving nursery pig performance. J Swine Health Prod 12: 296-307

Munz C, Steinman RM, Fujii S 2005: Dendritic cell maturation by innate lymphocytes: coordinated stimulation of innate and adaptive immunity. J Exp Med 202: 203-207 
Pistl J, Kovalkovičová N, Holovská V, Legáth J, Mikula I 2003: Determination of the immunotoxic potential of pesticides on functional activity of sheep leukocytes in vitro. Toxicology 188: 73-81

Podmanický D, Kováč G 2000: Lawsoniosis in swine - proliferative hemorrhagic enteropathy (ileitis) (In Slovak). Infovet 5: 203-206

Podmanický D, Kováč G, Reichel P 1999: After-weaning diarrheal diseases in swine. In: Colective of authors: Current health problems of pigs. Košice: 63-69

Slanina L, Vajda V, Blažej J 1976: Turbidimetric analysis of immunoglobulins in calves and their clinical evaluation. Veterinářství 9: 392-394

Šajgalík M 2007: Have we new diseases? Ileitis is caused by Lawsonia intracellularis (In Slovak). Slov Vet Čas 2: $78-80$

Trebichavský I, Toman M, Hořín P 2000: Immune system of swine (In Czech). In: Toman M et al.: Veterinární imunologie, Praha: 127-130

Wang Z, Guo YM, Yuan JM, Zhang BK 2008: Effect of dietary beta-1,3/1,6-glucan supplementation on growth performance, immune response and plasma prostaglandin E-2, growth hormone and ghrelin in weanling piglets. Asian-Aust J Anim Sci 21: 707-714

Willment JA, Gordon S, Brown GD 2001: Characterization of the human b-glucan receptor and its alternatively spliced isoforms. J Biol Chem 276: 43818-43823 